fall under the purview of the government's animal-research guidelines). Researchers applying to create these specific entities look set to have their requests granted, within the existing rules that no in vitro human embryo should be allowed to develop beyond 14 days, and no embryo derived from animal material should be implanted in a human uterus.

In the main, research advocates are satisfied with the proposal, and the government is to be applauded for not persisting with its plan for an outright ban. But a closer reading of the draft bill reveals that the proposed legislation is prescriptive, in mind-boggling detail, rather than truly permissive - and this is an approach that looks set to harm the field of embryology in the longer term.

The bill states that the creation of hybrid embryos "should not be permitted but that there should be a regulation-making power allowing exceptions to the prohibition". That power will be the Human Fertilisation and Embryology Authority (HFEA, which is to be rebranded as the Regulatory Authority for Tissue and Embryos), and those exceptions will be the various strictly defined techniques prescribed in the draft act.

But politicians are not embryology experts, and in attempting to compose a definitive list of acceptable techniques, they risk saddling researchers with a piece of legislation that does not allow the freedom to pursue new and promising possibilities not covered by the draft bill.
And no matter how thoroughly you consult stakeholders now, someone will come along in five or ten years' time and ask for permission to do something you hadn't thought of.

It was just such a situation that caused the recent ill-feeling over the government's handling of hybrid-embryo proposals. When separate research groups at Newcastle University and King's College London asked the HFEA last year for permission to create cybrid embryos, the agency panicked and referred the issue to the government, which proposed its infamous ban before later admitting that such research is necessary and useful. The proposed legislation will prompt a repeat performance every time researchers propose something that the regulatory body does not feel comfortable dealing with - and by inviting politicians into the fray with greater regularity, it encourages repeated attacks by those who want to see all work on human embryos outlawed.

Much better would be to preserve the spirit of Britain's 1990 Human Fertilisation and Embryology Act, which the draft bill is intended to replace. That act contained several general rules of thumb that have provided a useful ethical framework while not stifling research. Even 17 years down the line, those rules still stand up to scrutiny. Embryologists could look forward to a more fruitful future if they were given a regulatory body with the ethical muscle to approve novel techniques while adhering to tried and trusted principles.

\section{Nobels in dubious causes}

\section{Top scientists should campaign only where they can truly make a difference.}

W ith great power comes great responsibility, said the wise uncle of Peter Parker, a.k.a. Spiderman. The same might be true of Nobel laureates.

Every October, a new class of formerly obscure scientists is hurled into the limelight, their lives changing literally overnight with that phone call from Stockholm. Their daily routine changes from one of quiet hours in the lab to one encompassing many new demands on their time, from speaking engagements to invitations to sign the latest petition for peace and justice on the planet (see page 374).

In theory, this is a good thing. Most Nobel prizewinners are thoughtful people with insightful things to say about the world. And there is a rich history of prominent scientists playing crucial roles in major world decisions - Albert Einstein warning US President Franklin Roosevelt that the Germans might be thinking of building an atomic bomb, or the Federation of American Scientists drawing attention to the dangers of nuclear proliferation early in the atomic age.

But scientists need to take care not to overstep their expertise. It is reasonable to expect a Manhattan Project physicist to weigh in on the dangers of nuclear weapons, with which he or she is entirely familiar. It is less clear-cut to, say, support the candidacy of a politician.

In the United States, a group called Scientists and Engineers for America formed last year with the benevolent-sounding goals of good government, open debate, competent leadership and political participation. It sprang mainly, however, from years of frustration with the administration of President George W. Bush and its many instances of reportedly twisting science to its own ends. There is little doubt that US federal science has suffered under Bush, but it is unclear how this group will accomplish concrete goals to counter this.

Political advocacy can, in fact, be the trickiest road for a scientistactivist to navigate. Nobel-prizewinning economists, for instance, are routinely recruited to either side of US presidential campaigns, with their names trotted out like endorsements. In Scotland earlier this month, a group of 62 scientists (including Ian Wilmut, creator of Dolly the cloned sheep) wrote to The Herald newspaper, days before the country's elections, claiming that funding for science in Scotland would suffer in the event of "separation" from the United Kingdom. But the election wasn't about separation, it was about who was best equipped to run the Scottish parliament. The Scottish National Party won the election. In aligning themselves so clearly with the Labour Party's cack-handed attempts to scare its own former supporters back into the fold, the signatories at least ran the danger of seeming to be self-interested, grant-obsessed, and out of touch with people's desire for change.

Scientists who want to promote change in the world would be better off selecting their areas of activism carefully. Nobel laureates have a special responsibility, as they are regarded by the public with a level of awe. Many of them do use their names wisely to advance education or underappreciated areas of science. Last week, for instance, 40 of them helped launch a US\$10-million fund to support scientific research in the Middle East. Such efforts are targeted, specific and worthy of the Nobel name. 